\title{
Simultaneous determination of typical substituted and parent polycyclic aromatic hydrocarbons in water and solid matrix by gas chromatography-mass spectrometry
}

\author{
Meng Qiao ${ }^{\mathrm{a}, \mathrm{b}}$, Weixiao $\mathrm{Qi}^{\mathrm{a}}$, Huijuan Liu ${ }^{\mathrm{a}}$, Jiuhui $\mathrm{Qu}^{\mathrm{a}, *}$ \\ a State Key Laboratory of Environmental Aquatic Chemistry, Research Center for Eco-Environmental Sciences, Chinese Academy of Sciences, Beijing 100085 \\ China \\ ${ }^{\mathrm{b}}$ University of Chinese Academy of Sciences, Beijing 100049, China
}

\section{A R T I C L E I N F O}

\section{Article history:}

Received 6 February 2013

Received in revised form 14 March 2013

Accepted 15 March 2013

Available online 26 March 2013

\section{Keywords:}

GC-MS

Substituted PAH

$\mathrm{PAH}$

River

Extraction

Purification

\begin{abstract}
A B S T R A C T
Polycyclic aromatic hydrocarbons (PAHs) are likely to transform to more mutagenic and carcinogenic substituted polycyclic aromatic hydrocarbons (SPAHs) in the environment. To date, no literature has reported on an analytical method for SPAHs in the natural water environment (encompassing water, suspended particulate and sediment matrix). A robust and routine analytical method was developed for simultaneous detection of 13 typical SPAHs and 16 PAHs in the water environment in this work. The pretreatment and instrument analysis procedure were optimized for effective detection of the 29 targets species. Recovery of each target ranged from $60 \%$ to $120 \%$, except for benz [ $a$ ]anthracene-7,12-dione (BA7,12-D), which resulted from the transformation of 7-nitrobenz[ $a]$ anthracene (7-NBA). The high recovery of BA-7,12-D was relatively stable, so the detection results could be corrected. The method quantification limits ranged from $0.04 \mathrm{ng} / \mathrm{L}$ to $20.25 \mathrm{ng} / \mathrm{L}$ for $4 \mathrm{~L}$ water samples, from $4.12 \mathrm{ng} / \mathrm{g}$ to $131.66 \mathrm{ng} / \mathrm{g}$ for $0.1 \mathrm{~g}$ particulate samples, and from $1.75 \mathrm{ng} / \mathrm{g}$ to $28.04 \mathrm{ng} / \mathrm{g}$ for $20 \mathrm{~g}$ sediment samples. The method was applied to detect the 29 targets pollutants in polluted rivers, receiving wastewater from Beijing and Tianjin in China. Certain SPAH targets including 2-methylnaphthalene, 2,6-dimethylnaphthalene, 1-methylfluoranthene, 3,6-dimethylphenanthrene, 9-fluorenone, anthraquinone, 2-methylanthranquinone and BA-7,12-D were detected in the natural river environment, and all PAH targets were found in rivers.
\end{abstract}

(ㄷ) 2013 Elsevier B.V. All rights reserved.

\section{Introduction}

Substituted polycyclic aromatic hydrocarbons (SPAHs) ubiquitously exist in the environment because of their widespread emission sources and the reaction of parent polycyclic aromatic hydrocarbons (PAHs) with $\mathrm{NO}_{x}, \mathrm{OH}$ and $\mathrm{O}_{3}$ in the atmosphere [1-3] and transformation of PAHs in the soils [4]. They are some of the derivatives of the parent PAHs, such as nitro-PAHs (NPAHs), oxy-PAHs (OPAHs) and methyl-PAHs (MPAHs). Bamford and Baker figured out that 1-nitropyrene was the most abundant NPAH in the atmosphere, originating from the incomplete combustion of diesel fuels, and 9-nitroanthracene and 3-nitrofluoranthene were emitted directly from diesel engines [5]. OPAHs such as 9,10-anthraquione and 9-fluorenone in the atmosphere were mainly formed by the reaction of PAHs with ozone [6]. MPAHs were mainly generated from the combustion of petroleum $[7,8]$. Although these SPAHs are present at lower levels than parent

\footnotetext{
* Corresponding author. Tel.: +86 10 62849151; fax: +861062923558.

E-mail address: jhqu@rcees.ac.cn (J. Qu).
}

PAHs, their toxicities are much larger $[9,10]$. It has been well established that NPAHs are a kind of direct mutagenic and potential carcinogenic pollutant existing in the atmosphere $[11,12]$. Thus, a large number of studies on the analysis, distribution and sources of SPAHs in the atmosphere and soil had been conducted concerning their possible exposure risk [4,7,13-15]. SPAHs are thought to enter the water environment through precipitation, atmospheric sedimentation and surface runoff. The probable transformation from PAHs to SPAHs in the water environment may also contribute to an increase in pollution levels. However, only slight attention has been paid to these pollutants in the water environment.

To study the pollution levels of SPAHs and the photochemical transformation of PAHs and SPAHs in the water environment, a practical and simultaneous analytical method for both PAHs and different types of SPAHs is desirable. Analytical methods for PAHs in water, particulate and sediment phase samples have been well reported and applied [16-19], but for SPAHs were relatively limited. Previous methods have been developed on the analysis of NPAHs and OPAHs in air and soil, but not for the water environment. Sometimes, HPLC with fluorescence detection [20,21] and GC/ECD have been used for the detection of OPAHs and NPAHs [22,23], 
meanwhile GC/MS with EI (electron impact) or NICI (negative ion chemical ionization) source were used for the identification of each target compound. Usually, GC/MS-EI has been used for both quantitative and qualitative detection of OPAHs and MPAHs [24-26], and GC/MS-NICI for NPAHs and OPAHs [5,27,28]. Soxhlet extraction, accelerated solvent extraction and supercritical fluid extraction have mostly been used for the extraction of SPAHs [5,23,24,27]. Matrix effects could not be ignored. A clean-up procedure was found to be necessary prior to the instrumental analysis procedures. Silica cartridges [22,27], alumina cartridges [27] or HPLC [14] have always been used during the clean-up procedure. Although there have been some research focusing on the determination of SPAHs in air and soil samples, especially a single type of SPAHs, such as NPAHs [29,30] or OPAHs [31], and a recent study solely focusing on the determination of NPAHs in aqueous samples [32], the analytical methods of SPAHs in the natural water environment have not been well documented. Moreover, the existing methods used in air and soil samples are rather complicated. The ion source and GC column in GC-MS have to be changed during the detection procedure for MPAHs, NPAHs, OPAHs and PAHs [14,26,28]. Thus, it is imperative to develop an appropriate and convenient analytical method in different matrices of the water environment, for the determination of different types of SPAHs (including MPAHs, OPAHs and NPAHs) and PAHs.

The objective of this work was to develop and validate a convenient routine analytical method for simultaneous identification of 3 types of representative SPAHs and the 16 parent PAHs. Solid phase extraction (SPE) for the pretreatment of SPAHs in water phase samples is successfully applied. The purification and instrument analysis procedure for simultaneous detection of both SPAHs and PAHs were also achieved. Thereafter, this method was successfully applied to investigate the pollution levels of these targets in the polluted river environment, including water, suspended particulate and sediment samples.

\section{Materials and methods}

\subsection{Chemicals}

Thirteen single SPAH standards, including 2methylnaphthalene (2-MN, in solid 100\%), 1-methylfluoranthene (1-MF, $\quad 10 \mu \mathrm{g} / \mathrm{mL}), \quad 2,6$-dimethylnaphthalene (2,6-DMN, in solid 100\%), 3,6-dimethylphenanthrene (3,6-DMP, in solid $100 \%$ ), 9-fluorenone (9-FL, in solid $100 \%$ ), anthraquinone (AQ $100 \mu \mathrm{g} / \mathrm{mL}$ ), 2-methylanthranquinone (2-MAQ in solid 99.0\%), benz[a]anthracene-7,12-dione (BA-7,12-D, $50 \mu \mathrm{g} / \mathrm{mL}$ ), 2-nitrofluorene (2-NF, in solid 99.9\%), 9-nitroanthrancene (9$\mathrm{NA}, 100 \mu \mathrm{g} / \mathrm{mL}$ ), 3-nitrofluoranthene (3-NF, in solid $100 \%$ ), 1-nitropyrene (1-NP, in solid 99.8\%) and 7-nitrobenz[a]anthracene (7-NBA, $100 \mu \mathrm{g} / \mathrm{mL}$ ), and sixteen USEPA priority PAHs, including naphthalene (Nap), acenaphthylene (Acy), acenaphthene (Ace), fluorene (Fluo), phenanthrene (Phe), anthracene (Ant), fluoranthene (Flua), pyrene (Pyr), benz $[a]$ anthracene (BaA), chrysene (Chry), benzo[b]fluoranthene (BbF), benzo[ $k]$ fluoranthene (BkF), benzo[a]pyrene (BaP), indeno[1,2,3-cd]pyrene (IcdP), dibenz $[a, h]$ anthracene (DBA), and benzo[g,h,i]perylene (BghiP), in a mixture $(200 \mu \mathrm{g} / \mathrm{mL})$ were purchased from AccuStandard, Inc., New Haven, USA. Internal standards for 2-fluorobiphenyl (2-FB, in solid $>96 \%$ ) and decachlorobiphenyl (PCB209) were obtained from Aldrich Chemical Co., Inc. (Gillingham, Dorset, UK).

Hexane (HEX, Fisher Scientific, USA), dichloromethane (DCM, J. T. Baker, USA), methanol (Meth, Fisher Scientific, USA) and acetone (ACE, Dikma Technologies, USA) were HPLC grade solvents. Silica gel (0.06-0.2 mm) and alumina (100-200 mesh) for chromatography were purchased from Acro Organics, Inc. New Jersey,
USA. Before use, silica gel and alumina were baked at $180^{\circ} \mathrm{C}$ and $250{ }^{\circ} \mathrm{C}$ respectively for $12 \mathrm{~h}$, and then deactivated with $3 \%$ redistilled water, and kept in hexane until use. Anhydrous sodium sulfate (Tianjin, China) was baked at $450^{\circ} \mathrm{C}$ for $5 \mathrm{~h}$.

\subsection{Pretreatment procedures}

Water samples were extracted using reversed solid phase extraction (SPE) with C18 cartridges ( $500 \mathrm{mg}, 6 \mathrm{ml}$, Supelco) and HLB cartridges (500 mg, $6 \mathrm{ml}$, Waters), and then eluted with organic solvent. Suspended particulate and sediment samples were extracted using accelerated solvent extraction (ASE300, Donex) with 1:1 ACE: DCM for 10 min for two static cycles. The extraction temperature was $120^{\circ} \mathrm{C}$ and pressure was 1500 psi. After solvent exchange and concentration, samples were purified with silica gel/alumina cartridges ( $1 \mathrm{~cm}$ I.D., $6 \mathrm{~cm}$ alumina, $12 \mathrm{~cm}$ silica gel and $2 \mathrm{~cm}$ sodium sulfate). Fractions were concentrated to $0.5 \mathrm{~mL}$ under a gentle stream of nitrogen. The internal standards (100 ng) were added to each sample before instrumental analysis.

\subsection{Instrument analysis}

Targets were detected by an Agilent 7890A GC equipped with a $5795 \mathrm{C}$ mass spectrometry detector (GC-MS) with EI source in the selective ion monitoring (SIM) mode. A DB-17MS fused silica capillary column ( $30 \mathrm{~m}$ length $\times 0.25 \mathrm{~mm}$ diameter $\times 0.25 \mu \mathrm{m}$ film thickness) was used for the separation of each compound. Samples $(1 \mu \mathrm{L})$ were injected in splitless mode. The carrier gas was helium at a rate of $1 \mathrm{~mL} / \mathrm{min}$. Injector and detector temperatures were kept at $280^{\circ} \mathrm{C}$ and $290^{\circ} \mathrm{C}$, respectively. The program procedure for SPAHs and PAHs was as follows: $60^{\circ} \mathrm{C}$ (held for $1 \mathrm{~min}$ ), to $110^{\circ} \mathrm{C}$ at a rate of $20^{\circ} \mathrm{C} / \mathrm{min}$, and to $290^{\circ} \mathrm{C}$ at $3^{\circ} \mathrm{C} / \mathrm{min}$ (held for $20 \mathrm{~min}$ ).

A mixed standard $(500 \mu \mathrm{g} / \mathrm{L})$ was first analyzed at full-scan mode for the identification of the quantification ion, confirmation ion and the retention time of each standard. A mass range of $m / z$ $50-500$ was used in full-scan mode at a scan rate of $2.91 \mathrm{scan} / \mathrm{s}$. Then, for the SIM mode, the chromatogram was divided into several retention time windows for 31 compounds based on the results of full-scan mode. The transfer line and ion source temperature were $290^{\circ} \mathrm{C}$ and $230^{\circ} \mathrm{C}$, respectively. For each compound, quantification ions and confirmation ions were used for qualitative analysis and quantification ions were used for quantitative analysis (see Table 1).

\subsection{Sampling}

Water and sediment samples were collected from wastewater receiving rivers in the Haihe catchment located in Beijing and Tianjin, China. Water samples (including water phase and particulate phase) were collected at four sites (R1, R2, R3 and R4) in August, 2011, and sediment samples were collected at three sites (SA, SB and SC) in December, 2011. The details of sample locations and physical-chemical parameters are listed in Table S1. Water samples were filtered through glass microfiber filters (Whatman $\mathrm{GF} / \mathrm{F}, 142 \mathrm{~mm}$ diameter, $0.7 \mu \mathrm{m}$ pore size) pre-combusted at $450^{\circ} \mathrm{C}$ for $5 \mathrm{~h}$. The water phase samples were extracted within 2 days, and suspended particulate and sediment samples were stored in a refrigerator at $-20^{\circ} \mathrm{C}$ until analysis. All the samples were stored in darkness.

\subsection{Method validation}

A seven-point calibration curve with internal standards was prepared, established based on the peak area ratios of each target to its corresponding internal standard. The concentrations of each internal standard were $200 \mathrm{ng} / \mathrm{mL}$ in the calibration solutions. 
Table 1

Retention time and ions for each compound monitored by GC-MS-SIM.

\begin{tabular}{|c|c|c|c|c|c|}
\hline Target (abbreviation) & Type & Peak number & Retention time (min) & Quantification ion $(m / z)$ & Confirmation ion $(\mathrm{m} / \mathrm{z})$ \\
\hline Naphthalene (Nap) & PAH & 1 & 8.71 & 128 & 102 \\
\hline 2-Methylnaphthanlene (2-MN) & SPAH & 2 & 11.39 & 142 & 126,115 \\
\hline 2-Fluobiphenyl (2-FB) & ISTD & 3 & 13.66 & 172 & 151,146 \\
\hline 2,6-Dimethylnaphthalene (2,6-DMN) & SPAH & 4 & 14.51 & 156 & 141,128 \\
\hline Acenaphthylene (Acy) & $\mathrm{PAH}$ & 5 & 17.83 & 152 & 76,126 \\
\hline Acenaphthene (Ace) & PAH & 6 & 18.73 & 154 & 76,126 \\
\hline Fluorene (Fluo) & $\mathrm{PAH}$ & 7 & 22.28 & 166 & 115,139 \\
\hline 9-Fluorenone (9-FL) & SPAH & 8 & 29.38 & 180 & 152,126 \\
\hline Phenanthrene (Phe) & РAH & 9 & 30.45 & 178 & 89,152 \\
\hline Anthracene (Ant) & РАH & 10 & 30.67 & 178 & 89,152 \\
\hline 3,6-Dimethylphenanthrene (3,6-DMP) & SPAH & 11 & 36.80 & 206 & 191,178 \\
\hline Anthraquione (AQ) & SPAH & 12 & 38.40 & 208 & 180,152 \\
\hline Fluoranthene (Flua) & РАH & 13 & 40.21 & 202 & 150,174 \\
\hline 2-Methylanthraquinone (2-MAQ) & SPAH & 14 & 42.20 & 222 & $207,194,165$ \\
\hline Pyrene (Pyr) & $\mathrm{PAH}$ & 15 & 42.42 & 202 & 101,174 \\
\hline 2-Nitrofluorene (2-NF) & SPAH & 16 & 42.54 & 211 & 194,165 \\
\hline 9-Nitroanthracene (9-NA) & SPAH & 17 & 43.54 & 223 & 193,176 \\
\hline 1-Methylfluoranthene (1-MF) & SPAH & 18 & 44.59 & 216 & 200,189 \\
\hline Benz $[a]$ anthracene $(\mathrm{BaA})$ & $\mathrm{PAH}$ & 19 & 52.23 & 228 & 113,200 \\
\hline Chrysene (Chry) & $\mathrm{PAH}$ & 20 & 52.88 & 228 & 113,200 \\
\hline 3-Nitrofluoranthene (3-NF) & SPAH & 21 & 55.82 & 247 & 217,200 \\
\hline Benz[a]anthrancene-7,12-dione (BA-7,12-D) & SPAH & 22 & 56.90 & 258 & 230,202 \\
\hline 1-Nitropyrene (1-NP) & SPAH & 23 & 57.75 & 247 & 217,201 \\
\hline Decachlorobiphenyl (РCB209) & ISTD & 24 & 59.28 & 498 & 430 \\
\hline Benzo[b]fluoranthene (BbF) & PAH & 25 & 60.73 & 252 & 126,224 \\
\hline Benzo[k]fluoranthene $(\mathrm{BkF})$ & $\mathrm{PAH}$ & 26 & 60.91 & 252 & 126,224 \\
\hline 7-Nitrobenz $[a]$ anthracene (7-NBA) & SPAH & 27 & 61.90 & 273 & 226,215 \\
\hline Benzo $[a]$ pyrene $(\mathrm{BaP})$ & $\mathrm{PAH}$ & 28 & 63.66 & 252 & 126,224 \\
\hline Indeno[1,2,3-cd]pyrene (IcdP) & PAH & 29 & 73.46 & 276 & 138 \\
\hline Dibenz $[a, h]$ anthracene (DBA) & PAH & 30 & 73.77 & 278 & 139 \\
\hline Benzo[g,h,i]perylene (BghiP) & $\mathrm{PAH}$ & 31 & 77.47 & 276 & 138 \\
\hline
\end{tabular}

The recovery of each target were performed in both blank and matrix samples. A mixture of the 29 targets ( $250 \mathrm{ng}$ for each compound) was used to spike water and solid samples for the determination of the recovery of the 29 targets in blank and matrix samples.

The method detection limits (MDLs) and the method quantification limits (MQLs) were calculated based on a standard deviation of seven matrix samples spiked with target analytes at concentrations of 3 and 10 times the signal to noise ratio.

\section{Results and discussion}

\subsection{GC-MS parameters optimization}

A satisfactory separation of the thirteen SPAH targets and sixteen PAH targets could be achieved (Fig. 1) using GC-MSEI in SIM mode equipped with a DB-17MS column. Usually, parent PAHs [16] and MPAHs [25] were separated with HP-5MS column, and detected using GC-MS equipped with EI source; NPAHs have been customarily separated with HP-5MS or DB17MS column, and detected with NICI source [26-30,32]; OPAHs could be detected both with EI [24] source and NICI source [27]. Result of this work demonstrated that GC-MS-EI equipped with a DB-17MS column could not only be used for the separation and detection of SPAHs, but also for PAHs, because of the suitable polarity of these compounds. The use of DB-17MS column and EI source simplified the instrument analytical procedures, allowing research on the determination of PAHs and SPAHs.

The peak numbers and names are listed in Table 1. Peak 15 and 16 could not be completely separated in SIM mode, but could be quantified by the one-ion-quantitative method (Fig. 1). Thus, SIM mode and the one-ion-quantitative method yielded sufficient selectivity and sensitivity.

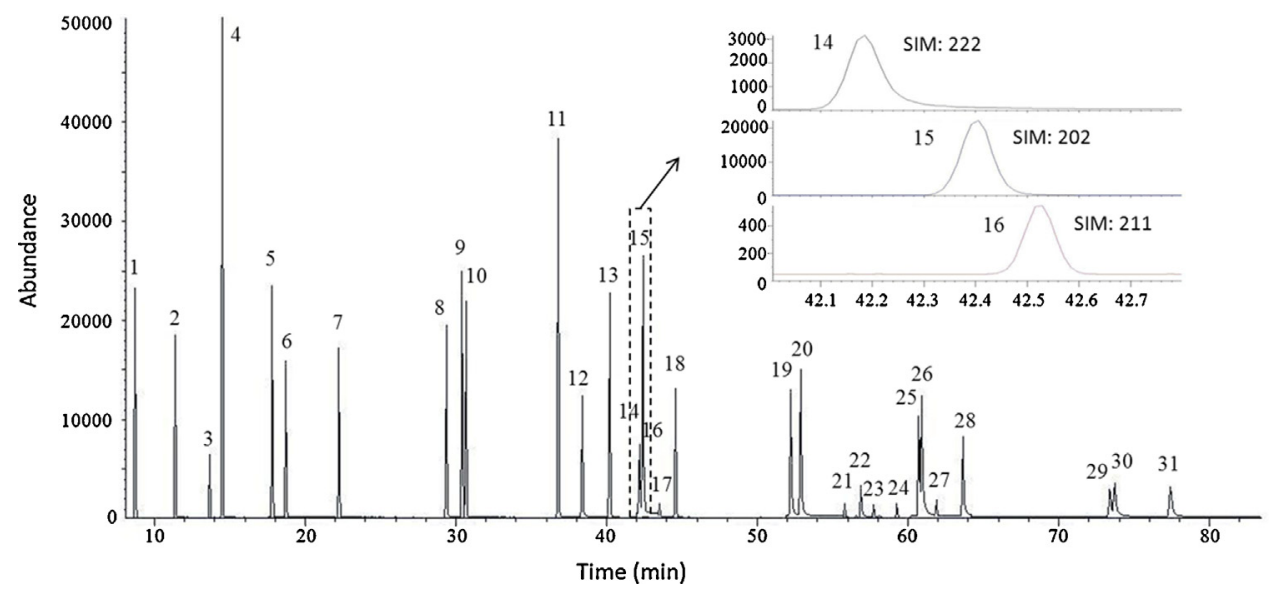

Fig. 1. GC-MS-SIM chromatogram for 29 SPAH and PAH targets and 2 internal standards: The corresponding peak-numbered compounds are shown in Table 1. 


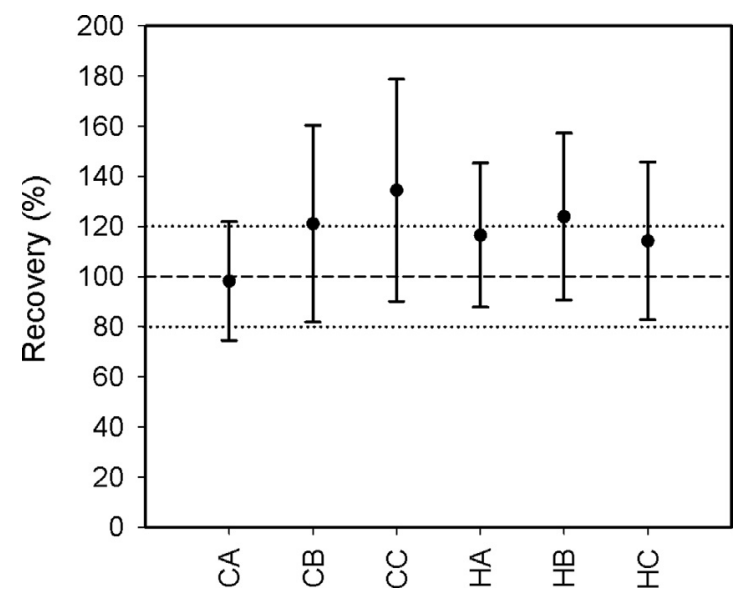

Fig. 2. Average recoveries of the $13 \mathrm{SPAH}$ targets $\pm \mathrm{SD}(n=13)$ during the SPE procedure: CA, C18 with $10 \mathrm{ml}$ DCM and $5 \mathrm{ml}$ HEX; CB, C18 with $15 \mathrm{ml} \mathrm{DCM}$; CC, C18 with $10 \mathrm{ml}$ ACE and $5 \mathrm{ml} \mathrm{DCM}$; HA, HLB with $10 \mathrm{ml}$ DCM and $5 \mathrm{ml}$ HEX; HB, HLB with $15 \mathrm{ml}$ DCM; HC, HLB with $10 \mathrm{ml}$ ACE and $5 \mathrm{ml} \mathrm{DCM}$.

\subsection{Selection of extraction procedures}

Due to the similarity of character between PAHs and SPAHs, the pretreatment procedures of SPAHs had been established on the basis of PAHs [33,34]. However, because the polarities of SPAHs were somewhat different from PAHs as indicated in the above discussion on GC-MS column choosing, the procedure was optimized in this study.

\subsubsection{Selection of extraction procedures for water samples}

Based on the extraction method of PAHs from water phase samples, SPE was used in this procedure. The efficiency of different cartridges and different eluting solvents were compared for the extraction of the 13 SPAHs. The average recoveries of the 13 SPAH targets and standard deviations are shown in Fig. 2.

The recoveries of the 13 SPAH compounds extracted with C18 cartridges and eluted with $10 \mathrm{ml}$ DCM followed by $5 \mathrm{ml}$ HEX (CA) were between $53.9 \%(2-\mathrm{MN})$ and $120.3 \%$ (BA-7,12-D) with a mean recovery of $98.2 \%$, proximal to $100 \%$. The average recoveries for other conditions (C18 cartridges with $15 \mathrm{ml} \mathrm{DCM}$ for CB, C18 cartridges with $10 \mathrm{ml} \mathrm{ACE}$ and $5 \mathrm{ml}$ DCM for CC) and HLB cartridges were higher than $100 \%$ (Fig. 2). Meanwhile, the standard deviation of the 13 SPAH compounds by CA was $23.71 \%$, lower than other extraction conditions, indicating that CA was the most stable condition. The stronger polarity of HLB cartridges and the eluting solvent of $\mathrm{CB}$ and $\mathrm{CC}$ might import some compounds more polar than SPAHs during the extraction procedure, which could possibly interfere with the targets' concentrations [35]. Due to the stability condition of CA it could be employed for the extraction part of the pretreatment procedure. Additionally, this condition matches that of a previous PAHs extraction study [34], thus allowing simultaneous extraction of PAHs and SPAHs from water phase samples.

\subsubsection{Selection of extraction procedures for solid samples}

As a result of the fact that the SPAHs extraction procedures of water samples were the same as those for PAHs, the procedures for extracting PAHs from particulate samples could possibly be used for SPAHs. The experiment was carried out as described in Section 2.3. The recovery result showed that the ASE procedure for PAHs was also suitable for SPAHs. The recoveries of the 13 targets ranged from $68.0 \%$ to $150.0 \%$. The reason for the high recovery will be explained in Section 3.3.

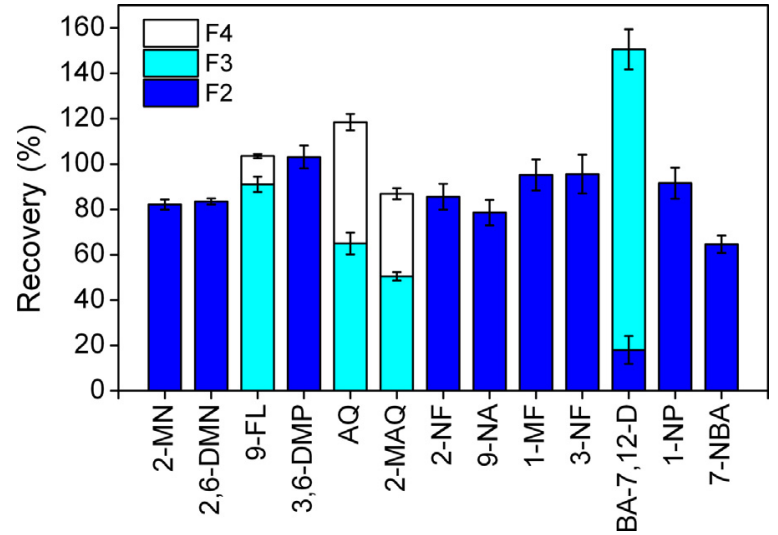

Fig. 3. Average recoveries of each compound $\pm S D(n=3)$ during the purification procedure: F2, eluted with $75 \mathrm{ml}$ 3:7 DCM:HEX for fraction 2; F3, eluted with $60 \mathrm{ml}$ 1:1 DCM:HEX for fraction 3; F4, eluted with $60 \mathrm{ml}$ 7:3 DCM:HEX for fraction 4.

\subsection{Optimization of purification procedures}

Elution solvents of different polarity were tested to arrive at the best choice. The fraction separation condition was as follows: fraction 1 (F1, $15 \mathrm{ml} \mathrm{HEX),} \mathrm{fraction} 2$ (F2, $75 \mathrm{ml}$ 3:7 DCM:HEX), fraction 3 (F3, $60 \mathrm{ml}$ 1:1 DCM:HEX), fraction 4 (F4, $60 \mathrm{ml} \mathrm{7:3} \mathrm{DCM:HEX)} \mathrm{and}$ fraction $5(\mathrm{~F} 5,60 \mathrm{ml} \mathrm{DCM})$. The recoveries of each fraction and total recovery are shown in Fig. 3.

Some compounds, including 9-FL, AQ and 2-MAQ, could not be eluted with fraction 2 . They existed in fraction 3 and fraction 4 . BA7,12-D existed in fraction 2 and fraction 3. Other compounds could be almost completely eluted with fraction 2 . This might be influenced by the adsorption of the different substituent groups on the silica gel and alumina. 9-FL, AQ 2-MAQ and BA-7,12-D were harder to elute than other compounds, probably because the adsorption of carbonyl groups on silica gel and alumina might be stronger than methyl (2-MN, 2,6-DMN, 3,6-DMP and 1-MF) and nitro (2-NF, 9-NA 3-NF, 1-NP and 7-NBA) groups. The total recoveries of each compound in all fractions were between $82.2 \%$ and $103.6 \%$, except for AQ (118.5\%), BA-7,12-D (150.6\%), 9-NA (78.6\%) and 7-NBA (64.6\%). The lower recoveries of 9-NA and 7-NBA and the higher recoveries of $A Q$ and $B A-7,12-D$ might be induced by the photochemical transformation from 9-NA to AQ [36] and from 7-NBA to BA-7,12-D [37]. No targets existed in fraction 1 and fraction 5 .

A previous study indicated that the $16 \mathrm{PAH}$ compounds existed totally in fraction 2 [38], implying that SPAHs and PAHs could also be purified during one procedure.

\subsection{Method validation}

To validate the application of the above method to water, suspended particulate and sediment matrix samples, recoveries, MDLs/MQLs and laboratory background levels of each target were determined in this section.

\subsubsection{Recoveries of the pretreatment procedure}

Pretreatment experiments were carried out using blank and matrix samples spiked with both the 13 SPAH targets and $16 \mathrm{PAH}$ targets. The extraction and purification procedure were carried out following results from Sections 3.2 and 3.3.

3.4.1.1. Recoveries of SPAHs and PAHs in water phase samples. Triplicate $4 \mathrm{~L}$ deionized water and $4 \mathrm{~L}$ polluted-river water samples spiked with the 29 targets were used as spiked blank samples and spiked matrix samples. The recoveries and standard deviations of each compound are shown as Table 2. 
Table 2

Recoveries of SPAHs and PAHs in spiking blank and matrix samples of water and solid phase (mean (\%) \pm standard deviation (\%), $n=3$ ).

\begin{tabular}{|c|c|c|c|c|c|}
\hline \multirow[t]{2}{*}{ Compounds } & \multicolumn{2}{|l|}{ Water phase } & \multicolumn{3}{|l|}{ Solid phase } \\
\hline & Blank & Matrix & Blank & Particulate matrix & Sediment matrix \\
\hline $2-\mathrm{MN}^{\mathrm{a}}$ & $62.3 \pm 12.3$ & $81.3 \pm 11.4$ & $74.4 \pm 15.2$ & $59.7 \pm 19.4$ & $68.7 \pm 8.1$ \\
\hline 2,6-DMN & $78.0 \pm 6.2$ & $86.6 \pm 8.4$ & $80.3 \pm 10.6$ & $63.3 \pm 9.8$ & $67.1 \pm 2.4$ \\
\hline 9-FL & $100.5 \pm 6.7$ & $75.1 \pm 7.5$ & $93.2 \pm 8.4$ & $87.4 \pm 4.1$ & $101.8 \pm 14.1$ \\
\hline 3,6-DMP & $91.9 \pm 2.2$ & $96.5 \pm 7.6$ & $95.0 \pm 5.8$ & $86.8 \pm 3.9$ & $114.5 \pm 4.5$ \\
\hline $\mathrm{AQ}$ & $84.1 \pm 7.4$ & $70.0 \pm 2.2$ & $123.5 \pm 10.8$ & $107.1 \pm 4.1$ & $125.1 \pm 13.7$ \\
\hline 2-MAQ & $66.1 \pm 7.8$ & $83.9 \pm 11.4$ & $107.2 \pm 7.1$ & $98.1 \pm 3.5$ & $110.0 \pm 11.3$ \\
\hline $2-\mathrm{NF}$ & $100.0 \pm 6.9$ & $83.4 \pm 10.6$ & $88.4 \pm 11.3$ & $85.9 \pm 4.0$ & $95.4 \pm 3.3$ \\
\hline $9-N A$ & $86.3 \pm 1.2$ & $74.7 \pm 6.7$ & $93.5 \pm 16.3$ & $60.0 \pm 8.1$ & $76.3 \pm 10.0$ \\
\hline 1-MF & $97.0 \pm 3.5$ & $106.3 \pm 6.6$ & $105.6 \pm 6.2$ & $95.6 \pm 3.9$ & $112.8 \pm 1.5$ \\
\hline $3-N F$ & $96.9 \pm 6.8$ & $89.6 \pm 4.2$ & $68.0 \pm 9.5$ & $89.2 \pm 7.8$ & $77.8 \pm 13.4$ \\
\hline BA-7,12-D & $158.5 \pm 3.3$ & $154.7 \pm 8.1$ & $138.8 \pm 21.1$ & $155.9 \pm 10.6$ & $147.8 \pm 14.8$ \\
\hline $1-\mathrm{NP}$ & $96.1 \pm 6.1$ & $99.4 \pm 4.7$ & $97.8 \pm 14.8$ & $103.6 \pm 4.2$ & $122.7 \pm 14.6$ \\
\hline 7-NBA & $45.3 \pm 2.3$ & $60.7 \pm 6.3$ & $78.9 \pm 6.9$ & $73.1 \pm 8.6$ & $82.9 \pm 11.1$ \\
\hline Nap & $50.4 \pm 5.0$ & $89.4 \pm 20.6$ & $73.7 \pm 5.3$ & $49.6 \pm 15.7$ & $40.4 \pm 6.7$ \\
\hline Acy & $62.7 \pm 4.0$ & $71.8 \pm 17.1$ & $67.7 \pm 4.8$ & $64.4 \pm 6.3$ & $72.8 \pm 7.1$ \\
\hline Ace & $87.7 \pm 8.1$ & $104.9 \pm 8.9$ & $80.8 \pm 5.4$ & $72.7 \pm 7.0$ & $77.9 \pm 5.6$ \\
\hline Fluo & $102.3 \pm 7.5$ & $119.8 \pm 17.8$ & $84.7 \pm 5.9$ & $70.7 \pm 2.2$ & $83.3 \pm 6.6$ \\
\hline Phe & $90.5 \pm 4.9$ & $113.0 \pm 8.0$ & $90.3 \pm 9.8$ & $63.9 \pm 12.2$ & $90.2 \pm 11.8$ \\
\hline Ant & $81.2 \pm 8.7$ & $88.9 \pm 9.7$ & $75.4 \pm 10.1$ & $78.8 \pm 2.8$ & $101.3 \pm 4.7$ \\
\hline Flua & $115.2 \pm 4.5$ & $106.1 \pm 8.2$ & $98.5 \pm 4.0$ & $86.8 \pm 5.0$ & $120.6 \pm 2.8$ \\
\hline Pyr & $113.8 \pm 4.3$ & $102.7 \pm 7.1$ & $97.6 \pm 3.2$ & $87.2 \pm 4.6$ & $122.5 \pm 3.0$ \\
\hline $\mathrm{BaA}$ & $114.1 \pm 7.3$ & $84.5 \pm 7.8$ & $109.3 \pm 1.0$ & $100.0 \pm 5.1$ & $108.8 \pm 7.9$ \\
\hline Chry & $109.0 \pm 6.8$ & $88.2 \pm 7.1$ & $106.1 \pm 2.2$ & $95.7 \pm 6.4$ & $81.5 \pm 4.0$ \\
\hline $\mathrm{BbF}$ & $109.9 \pm 14.6$ & $98.2 \pm 5.1$ & $116.1 \pm 5.3$ & $110.4 \pm 6.4$ & $116.1 \pm 12.6$ \\
\hline $\mathrm{BkF}$ & $96.8 \pm 12.6$ & $65.7 \pm 3.5$ & $108.5 \pm 2.1$ & $98.2 \pm 5.0$ & $105.1 \pm 10.3$ \\
\hline $\mathrm{BaP}$ & $98.2 \pm 15.0$ & $76.3 \pm 6.6$ & $102.7 \pm 0.5$ & $111.3 \pm 6.5$ & $111.5 \pm 3.2$ \\
\hline IcdP & $94.4 \pm 25.7$ & $83.8 \pm 6.8$ & $124.8 \pm 12.7$ & $123.3 \pm 13.8$ & $138.9 \pm 2.9$ \\
\hline DBA & $81.0 \pm 14.2$ & $72.4 \pm 6.0$ & $126.2 \pm 12.6$ & $115.4 \pm 14.3$ & $123.3 \pm 0.8$ \\
\hline BghiF & $84.0 \pm 20.8$ & $60.2 \pm 3.4$ & $119.0 \pm 8.3$ & $127.7 \pm 12.4$ & $132.5 \pm 9.5$ \\
\hline
\end{tabular}

a See the full name of the analytes in Table 1.

The recoveries of SPAHs ranged from $62.3 \%$ to $100.5 \%$, except for 7-NBA (45.3\%) and BA-7,12-D (158.5\%) for spiked blank samples. For spiked matrix samples, the recoveries of SPAHs were between $70.0 \%$ and $106.3 \%$, except for $7-\mathrm{NBA}(60.7 \%)$ and BA-7,12-D (154.7\%). The low recovery of 7-NBA and high recovery of BA-7,12-D were similar to their recovery in the purification procedure. By contrast, during the extraction procedure, the recoveries of these two compounds were in the normal range, indicating that the transformation from 7-NBA to BA-7,12-D occurred during the purification procedure. This might be induced by the comparatively long exposure time of the targets to light, although effort had been made to reduce the targets exposure time to light. However, the results were quite stable because the standard deviations for 7-NBA and BA-7,12-D were $3.3 \%$ and $2.3 \%$ for spiked blank samples, and $8.1 \%$ and $6.3 \%$ for spiked matrix samples. Thus, detection results could be corrected with the stable recovery of 7-NBA and BA-7,12-D. For the part of the 16 PAHs, the recoveries for both spiked blank and matrix samples were between $60 \%$ and $120 \%$, except for Nap (50.4\%), a relatively volatile compound. Standard deviation of each 29 target was less than $20 \%$ as specified in the USEPA recommendation [39], validating the method as stable for SPAHs and PAHs pretreatment in polluted water matrix samples.

3.4.1.2. Recoveries of SPAHs and PAHs in solid phase samples. The recoveries of SPAHs and PAHs were further examined in solid blank and matrix samples, including particulate samples and sediment samples. The results showed that the recoveries of SPAH compounds from spiked blank, particulate and sediment matrix samples were mostly between $60 \%$ and $120 \%$ (Table 2 ). The recoveries of AQ and BA-7,12-D were higher than $120 \%$, and 9-NA and 7-NBA were relatively low, demonstrating that during the pretreatment procedure of particulate samples, a small part of 9-NA and some 7-NBA also transformed to AQ and BA-7,12-D, respectively, as discussed above. The standard deviations were less than $20 \%$, indicating that both precision and accuracy were ensured for the pretreatment procedure used for the solid phase samples from polluted rivers. PAHs recoveries and standard deviations also validated the method for solid phase pretreatment.

3.4.1.3. Recoveries of 7-NBA and $B A-7,12-D$. The recoveries of BA-7,12-D and 7-NBA exceeded the regular recovery range recommended by the USEPA (70-120\%) [39], especially for BA-7,12-D (around 150\%). Therefore an experiment was carried out to investigate the recoveries of these two compounds respectively. The results (Table S2) showed that the average recovery of BA-7,12-D was $107.7 \%$ and $7-N B A$ was 0 when only BA-7,12-D was added to $4 \mathrm{~L}$ deionized water. However, when only 7-NBA was added, the mean recovery of BA-7,12-D was $29.0 \%$ and $7-\mathrm{NBA}$ was $67.0 \%$, and no BA7,12-D was detected in the 7-NBA standard before pretreatment, which was a confirmation of the higher BA-7,12-D recovery and the lower 7-NBA recovery. Meanwhile, the standard deviations were less than $6.3 \%$, indicating an ensured precision and accuracy for the experiment. It could be concluded that the 7-NBA did transform to BA-7,12-D during the pretreatment procedure, but the transformation quantity could be ensured because of the stable recovery of BA-7,12-D and 7-NBA. Thus these two compounds could also be effectively quantified with the recovery correction.

\subsubsection{Method detection and quantification limits}

The MDLs of the 29 targets ranged from $0.02 \mathrm{ng} / \mathrm{L}$ to $7.40 \mathrm{ng} / \mathrm{L}$ in $4 \mathrm{~L}$ water samples, from $2.06 \mathrm{ng} / \mathrm{g}$ to $43.35 \mathrm{ng} / \mathrm{g}$ in $0.1 \mathrm{~g}$ particulate samples, and from $0.65 \mathrm{ng} / \mathrm{g}$ to $9.64 \mathrm{ng} / \mathrm{g}$ in $20 \mathrm{~g}$ sediment samples. The MQLs of all the targets varied from $0.04 \mathrm{ng} / \mathrm{L}$ to $20.25 \mathrm{ng} / \mathrm{L}$ in $4 \mathrm{~L}$ water samples, from $4.12 \mathrm{ng} / \mathrm{g}$ to $131.66 \mathrm{ng} / \mathrm{g}$ in $0.1 \mathrm{~g}$ particulate samples, and from $1.75 \mathrm{ng} / \mathrm{g}$ to $28.04 \mathrm{ng} / \mathrm{g}$ in $20 \mathrm{~g}$ sediment samples (Table 3). The MDLs and MQLs of particulate samples were much higher than in sediment samples. The appearance of higher concentrations of each target compound in particulate samples than those 
Table 3

Method detection limits, method quantification limits and laboratory background levels.

\begin{tabular}{|c|c|c|c|c|c|c|c|c|}
\hline \multirow[t]{2}{*}{ Compound } & \multicolumn{3}{|l|}{$\operatorname{MDLs}(n=7)$} & \multicolumn{3}{|l|}{ MQLs $(n=7)$} & \multicolumn{2}{|c|}{ Blank concentrations $(n=3)$} \\
\hline & Water (ng/L) & Particulate (ng/g) & Sediment (ng/g) & Water (ng/L) & Particulate (ng/g) & Sediment (ng/g) & Water (ng/L) & Solid (ng/g) \\
\hline $2-\mathrm{MN}^{\mathrm{a}}$ & 7.40 & 43.35 & 3.13 & 20.25 & 131.66 & 7.02 & $<\mathrm{MQL}$ & $20.31 \pm 2.34^{b}$ \\
\hline 2,6-DMN & 1.84 & 6.77 & 1.33 & 5.48 & 20.12 & 3.96 & N.D. ${ }^{c}$ & N.D. \\
\hline $9-\mathrm{FL}$ & 1.44 & 15.14 & 1.27 & 4.56 & 38.27 & 3.22 & N.D. & N.D. \\
\hline 3,6-DMP & 0.22 & 7.26 & 0.65 & 0.58 & 24.93 & 2.23 & N.D. & N.D. \\
\hline $\mathrm{AQ}$ & 2.13 & 6.29 & 2.63 & 5.65 & 19.45 & 9.29 & N.D. & N.D. \\
\hline 2-MAQ & 0.74 & 8.87 & 3.95 & 2.56 & 24.53 & 10.92 & N.D. & N.D. \\
\hline $2-\mathrm{NF}$ & 1.80 & 4.93 & 6.66 & 7.10 & 18.94 & 24.91 & N.D. & N.D. \\
\hline 9-NA & 2.97 & 15.66 & 9.64 & 9.64 & 48.19 & 28.04 & N.D. & N.D. \\
\hline 1-MF & 0.19 & 5.79 & 1.91 & 0.79 & 21.14 & 6.00 & N.D. & N.D. \\
\hline $3-N F$ & 1.93 & 8.21 & 5.31 & 6.51 & 27.70 & 17.93 & N.D. & N.D. \\
\hline BA-7,12-D & 0.84 & 8.35 & 6.77 & 2.06 & 24.17 & 22.58 & N.D. & N.D. \\
\hline $1-\mathrm{NP}$ & 1.35 & 11.41 & 8.36 & 4.81 & 24.42 & 17.70 & N.D. & N.D. \\
\hline 7-NBA & 1.38 & 5.51 & 3.86 & 4.43 & 17.70 & 12.42 & N.D. & N.D. \\
\hline Nap & 3.10 & 16.04 & 3.85 & 11.46 & 59.16 & 7.96 & $33.45 \pm 0.66$ & $12.52 \pm 0.85$ \\
\hline Acy & 0.82 & 14.61 & 3.01 & 1.24 & 21.99 & 7.14 & N.D. & N.D. \\
\hline Ace & 0.33 & 5.80 & 1.13 & 1.54 & 22.93 & 3.66 & N.D. & N.D. \\
\hline Fluo & 3.43 & 17.48 & 0.82 & 4.52 & 23.04 & 1.75 & N.D. & N.D. \\
\hline Phe & 6.83 & 28.69 & 1.31 & 15.30 & 64.23 & 5.61 & $31.37 \pm 2.41$ & N.D. \\
\hline Ant & 0.91 & 4.39 & 0.75 & 1.67 & 8.09 & 2.06 & N.D. & N.D. \\
\hline Flua & 0.31 & 11.65 & 1.84 & 0.70 & 26.04 & 4.52 & N.D. & N.D. \\
\hline Pyr & 0.30 & 9.55 & 1.35 & 0.65 & 20.88 & 3.47 & N.D. & N.D. \\
\hline $\mathrm{BaA}$ & 1.25 & 3.38 & 1.90 & 2.04 & 5.51 & 6.17 & N.D. & N.D. \\
\hline Chry & 2.31 & 6.50 & 1.56 & 3.93 & 11.04 & 2.73 & N.D. & N.D. \\
\hline $\mathrm{BbF}$ & 1.10 & 3.01 & 2.48 & 2.22 & 6.10 & 4.97 & N.D. & N.D. \\
\hline $\mathrm{BkF}$ & 0.02 & 3.82 & 4.18 & 0.04 & 7.94 & 9.00 & N.D. & N.D. \\
\hline $\mathrm{BaP}$ & 0.31 & 2.06 & 4.20 & 0.62 & 4.12 & 13.43 & N.D. & N.D. \\
\hline IcdP & 0.62 & 6.93 & 2.86 & 1.10 & 12.20 & 5.76 & N.D. & N.D. \\
\hline DBA & 0.08 & 27.55 & 2.09 & 0.19 & 60.20 & 7.63 & N.D. & N.D. \\
\hline BghiF & 0.45 & 16.59 & 2.44 & 1.26 & 45.46 & 6.54 & N.D. & N.D. \\
\hline
\end{tabular}

a See the full name of the analytes in Table 1.

b Mean \pm standard deviation.

c Not detected.

in sediment samples is further discussed in Section 3.5. Additionally, this finding makes this method well-suited for the detection of SPAHs and PAHs in particulate samples.

\subsubsection{Laboratory background conditions}

Due to the widespread distribution of SPAHs in the environment, especially in the atmospheric environment, three blank samples for each water and solid phase were run to evaluate the background in our laboratory. Table 3 shows the background levels of each of the SPAH and PAH compounds in $4 \mathrm{~L}$ deionized water and $20 \mathrm{~g}$ anhydrous sodium sulfate through the pretreatment procedure.

The results indicated that Nap and Phe existed in water blank samples, and 2-MN, and Nap occurred in solid blank samples, while 2-MN existed but at less than the method quantification limits in water blank samples. Nap, Phe and 2-MN were the most frequently occurring PAHs and SPAHs in the surrounding atmosphere [26], due to their stronger volatility than other targets, inducing their existence in the blank samples.

\subsection{Application of the method to different matrix of the polluted-river samples}

The proposed method was used for analyzing the 29 targets in the wastewater receiving rivers. Four water samples (including water-phase and particulate-phase samples) and three sediment samples were collected from the rivers in the Haihe catchment. Each sample was analyzed in triplicate. The results are shown in Table 4.

Some MPAHs and OPAHs were detected in the water phase samples. The concentrations of 2-MN ranged from $30.07 \mathrm{ng} / \mathrm{L}$ to $73.01 \mathrm{ng} / \mathrm{L}$, which was the highest among SPAHs, while the levels of the two-methyl substituted PAH 2,6-DMN (from <MQL to
$11.81 \mathrm{ng} / \mathrm{L}$ ) were lower. Meanwhile, 3,6-DMP and 1-MF could not be detected in the water phase samples. The concentrations of 9FL, AQ, 2-MAQ and BA-7,12-D ranged from $16.05 \mathrm{ng} / \mathrm{L}$ to $33.02 \mathrm{ng} / \mathrm{L}$ from $20.09 \mathrm{ng} / \mathrm{L}$ to $37.03 \mathrm{ng} / \mathrm{L}$, from $6.07 \mathrm{ng} / \mathrm{L}$ to $8.38 \mathrm{ng} / \mathrm{L}$ and from $<\mathrm{MQL}$ to $7.49 \mathrm{ng} / \mathrm{L}$, respectively. However, no NPAHs were detected in any of the water phase samples. NPAHs present relatively low levels in the aqueous samples commonly ranged from $5.2 \mathrm{ng} / \mathrm{L}$ to $7.5 \mathrm{ng} / \mathrm{L}$ with a detection frequency of $14 \%$ [32]. It was reported that the solubility of NPAHs (9-NA, 2-NF, 3-NF and 1-NP) was above $10 \mu \mathrm{g} / \mathrm{L}[40]$, and that they existed in the atmosphere $[1,5]$. Thus the result indicated that NPAHs might have been transformed to other substituted PAHs in the water environment. Additionally, the experiment on the determination of the recoveries of 7-NBA and BA-7,12-D (Section 3.4.1.3) was a proof for this transformation.

In the particulate phase samples, all MPAHs and OPAHs were detectable, and NPAHs were not detected. The concentrations of 2-MN ranged from $521.77 \mathrm{ng} / \mathrm{g}$ to $804.25 \mathrm{ng} / \mathrm{g}$, also higher than other SPAHs as in the water phase, except for a maximum value of 2,6-DMN of $1291.60 \mathrm{ng} / \mathrm{g}$. 3,6-DMP and 1-MF existed in the particulate phase, varying from $62.89 \mathrm{ng} / \mathrm{g}$ to $139.96 \mathrm{ng} / \mathrm{g}$ and from $85.57 \mathrm{ng} / \mathrm{g}$ to $159.04 \mathrm{ng} / \mathrm{g}$. They were also lower than the methyl Nap substitutes. The levels of 9-FL, AQ, 2-MAQ and BA7,12-D varied from $192.66 \mathrm{ng} / \mathrm{g}$ to $410.52 \mathrm{ng} / \mathrm{g}$, from $242.07 \mathrm{ng} / \mathrm{g}$ to $362.12 \mathrm{ng} / \mathrm{g}$, from $167.07 \mathrm{ng} / \mathrm{g}$ to $395.80 \mathrm{ng} / \mathrm{g}$ and from $146.83 \mathrm{ng} / \mathrm{g}$ to $317.15 \mathrm{ng} / \mathrm{g}$. There were also no NPAHs detected in the particulate phase samples.

In the sediment samples, the concentrations of SPAHs were lower than in the particulate samples. As in the particulate samples, all MPAHs and OPAHs were detected, but no NPAHs existed.

All PAH targets were detected in the water, particulate and sediment samples. The concentrations of Nap and Phe appeared to be higher than other PAHs, especially in the water and particulate 
Table 4

Pollution levels of the 29 targets in water, particulate and sediment samples.

\begin{tabular}{|c|c|c|c|c|c|c|}
\hline & \multicolumn{2}{|c|}{ Water (ng/L) } & \multicolumn{2}{|c|}{ Particulate (ng/g) } & \multicolumn{2}{|c|}{ Sediment (ng/g) } \\
\hline & Min & Max & Min & Max & Min & Max \\
\hline $2-\mathrm{MN}^{\mathrm{a}}$ & 30.07 & 73.01 & 521.77 & 804.25 & 28.45 & 118.92 \\
\hline 2,6-DMN & $<\mathrm{MQL}$ & 11.81 & 152.33 & 1291.60 & 9.54 & 68.53 \\
\hline 9-FL & 16.05 & 33.02 & 192.66 & 410.52 & 4.86 & 66.50 \\
\hline 3,6-DMP & N.D. ${ }^{b}$ & N.D. & 62.89 & 139.96 & 2.70 & 10.26 \\
\hline AQ & 20.09 & 37.03 & 242.07 & 362.12 & 23.35 & 134.35 \\
\hline 2-MAQ & 6.07 & 8.38 & 167.07 & 395.80 & 11.14 & 188.95 \\
\hline $2-N F$ & N.D. & N.D. & N.D. & N.D. & N.D. & N.D. \\
\hline 9-NA & N.D. & N.D. & N.D. & N.D. & N.D. & N.D. \\
\hline 1-MF & N.D. & N.D. & 85.57 & 159.04 & 7.53 & 50.29 \\
\hline $3-N F$ & N.D. & N.D. & N.D. & N.D. & N.D. & N.D. \\
\hline BA-7,12-D & $<\mathrm{MQL}$ & 7.49 & 146.83 & 317.15 & N.D. & 93.13 \\
\hline $1-\mathrm{NP}$ & N.D. & N.D. & N.D. & N.D. & N.D. & N.D. \\
\hline 7-NBA & N.D. & N.D. & N.D. & N.D. & N.D. & N.D. \\
\hline Nap & 51.73 & 152.82 & 786.28 & 1240.38 & 16.90 & 98.80 \\
\hline Acy & 3.03 & 9.59 & 65.69 & 98.78 & 8.90 & 25.39 \\
\hline Ace & 6.95 & 48.98 & 48.69 & 77.39 & 5.87 & 12.75 \\
\hline Fluo & 23.57 & 58.03 & 202.47 & 266.76 & 13.38 & 92.84 \\
\hline Phe & 39.84 & 103.51 & 1006.35 & 1280.89 & 53.01 & 334.92 \\
\hline Ant & 4.97 & 11.39 & 127.56 & 280.58 & 18.39 & 60.48 \\
\hline Flua & 15.00 & 46.10 & 252.53 & 630.81 & 71.48 & 391.99 \\
\hline Pyr & 9.81 & 38.88 & 173.00 & 645.33 & 61.21 & 335.02 \\
\hline $\mathrm{BaA}$ & 6.92 & 9.54 & 143.19 & 248.79 & 45.57 & 239.41 \\
\hline Chry & 4.98 & 7.72 & 155.43 & 293.65 & 16.42 & 153.00 \\
\hline $\mathrm{BbF}$ & 6.39 & 9.10 & 210.04 & 462.63 & 64.27 & 404.10 \\
\hline $\mathrm{BkF}$ & 6.03 & 6.97 & 178.58 & 232.62 & 27.70 & 133.47 \\
\hline $\mathrm{BaP}$ & 6.04 & 6.73 & 168.28 & 340.52 & 75.98 & 418.58 \\
\hline IcdP & 6.89 & 11.03 & 216.24 & 655.85 & 87.12 & 573.77 \\
\hline DBA & 8.28 & 8.68 & 188.82 & 278.55 & 13.63 & 90.91 \\
\hline BghiF & 7.24 & 9.38 & 215.97 & 508.60 & 71.06 & 472.82 \\
\hline
\end{tabular}

a See the full name of the analytes in Table 1.

b Not detected.

samples. In the sediment samples, the PAHs with higher $\log K_{\mathrm{ow}}$ values occurred at more abundant levels.

\section{Conclusions}

In the present study, a method for simultaneously detecting 13 typical SPAHs and 16 PAHs in complex matrices was established. The recoveries ranged from $60 \%$ to $120 \%$ for most of the targets, except for BA-7,12-D, the recoveries of which were around $150 \%$, resulting from the transformation of 7-NBA. At the same time, the method for analyzing BA-7,12-D was relatively stable, so the detection results could be corrected. The method detection limits were between $0.02 \mathrm{ng} / \mathrm{L}$ and $7.40 \mathrm{ng} / \mathrm{L}$ in $4 \mathrm{~L}$ water samples, between $2.06 \mathrm{ng} / \mathrm{g}$ and $43.35 \mathrm{ng} / \mathrm{g}$ in $0.1 \mathrm{~g}$ particulate samples, and between $0.65 \mathrm{ng} / \mathrm{g}$ and $9.64 \mathrm{ng} / \mathrm{g}$ in $20 \mathrm{~g}$ sediment samples, for each of the 29 targets. The method quantification limits of all the targets ranged from $0.04 \mathrm{ng} / \mathrm{L}$ to $20.25 \mathrm{ng} / \mathrm{L}$ in $4 \mathrm{~L}$ water samples, from $4.12 \mathrm{ng} / \mathrm{g}$ to $131.66 \mathrm{ng} / \mathrm{g}$ in $0.1 \mathrm{~g}$ particulate samples, and from $1.75 \mathrm{ng} / \mathrm{g}$ to $28.04 \mathrm{ng} / \mathrm{g}$ in $20 \mathrm{~g}$ sediment samples.

This method was successfully applied to the simultaneous detection of SPAHs and PAHs in polluted river water, particulate and sediment samples. The results indicated that certain SPAH targets (MPAHs and OPAHs) and all PAH targets existed in rivers. Meanwhile, transformations of SPAHs might occur in the water environment. Thus, it would be significant to examine the pollution levels of PAHs and SPAHs using this method, and study the transformation between PAHs and SPAHs in the water environment in the future. A distinguishing feature of this method is the ability to be used for the detection of SPAHs and PAHs in atmospheric and soil samples. For further studies requiring the transformation/transport of SPAHs and PAHs, or forecasting their fate in the environment, this study presents an effective and efficient analytical method, which is significant for application to manage of these types of micropollutants.

\section{Acknowledgements}

This work was supported by National Natural Science Foundation of China (Grant No. 51138006), National Natural Science Foundation of China (Grant No. 41203069) and Special Fund of State Key Joint Laboratory of Environment Simulation and Pollution Control (Grant No. 12L02ESPC).

\section{Appendix A. Supplementary data}

Supplementary data associated with this article can be found, in the online version, at http://dx.doi.org/10.1016/ j.chroma.2013.03.044.

\section{References}

[1] M. Dimashki, S. Harrad, R.M. Harrison, Atmos. Environ. 34 (2000) 2459.

[2] J. Arey, B. Zielinska, R. Atkinson, A.M. Winer, T. Ramdahl, J.N. Pitts Jr., Atmos. Environ. (1967) 20 (1986) 2339.

[3] J.N. Pitts Jr., Atmos. Environ. (1967) 21 (1987) 2531.

[4] S. Lundstedt, P.A. White, C.L. Lemieux, K.D. Lynes, L.B. Lambert, L. Oberg, P. Haglund, M. Tysklind, Ambio 36 (2007) 475.

[5] H.A. Bamford, J.E. Baker, Atmos. Environ. 37 (2003) 2077.

[6] M. Tsapakis, E.G. Stephanou, Environ. Sci. Technol. 41 (2007) 8011.

[7] P. Di Filippo, C. Riccardi, D. Pomata, C. Gariazzo, F. Buiarelli, Water Air Soil Pollut. $211(2010) 231$.

[8] H.B. Lee, T.E. Peart, R.L. Hongyou, D.R. Gere, J. Chromatogr. A 653 (1993) 83.

[9] H. Tokiwa, Y. Ohnishi, H.S. Rosenkranz, Crit. Rev. Toxicol. 17 (1986) 23.

[10] J.L. Durant, W.F. Busby Jr., A.L. Lafleur, B.W. Penman, C.L. Crespi, Mutat. Res.-Gen. Tox. 371 (1996) 123.

[11] X.B. Xu, Environ. Chem. 3 (1984) 1 (in Chinese).

[12] J.N. Pitts, K.A. Van Cauwenberghe, D. Grosjean, J.P. Schmid, D.R. Fitz, W.L. Belser, G.P. Knudson, P.M. Hynds, Science 202 (1978) 515.

[13] M.T. Galceran, E. Moyano, J. Chromatogr. A 715 (1995) 41.

[14] M. Niederer, Environ. Sci. Pollut. Res. 5 (1998) 209.

[15] M. Vincenti, C. Minero, E. Pelizzetti, M. Fontana, R.D. Maria, J. Am. Soc. Mass Spectrom. 7 (1996) 1255.

[16] X.J. Luo, B.X. Mai, Q.S. Yang, J.M. Fu, G.Y. Sheng, Z.S. Wang, Mar. Pollut. Bull. 48 (2004) 1102. 
[17] L.Z. Zhu, Y.Y. Chen, R.B. Zhou, J. Hazard. Mater. 150 (2008) 308.

[18] J.H. Sun, G.L. Wang, Y. Chai, G. Zhang, J. Li, J.L. Feng, Ecotoxicol. Environ. Saf. 72 (2009) 1614.

[19] J.J. Langenfeld, S.B. Hawthorne, D.J. Miller, J. Pawliszyn, Anal. Chem. 65 (1993) 338.

[20] M. Murayama, P.K. Dasgupta, Anal. Chem. 68 (1996) 1226.

[21] T. Kamiura, T. Kawaraya, M. Tanaka, T. Nakadoi, Anal. Chim. Acta 254 (1991) 27.

[22] J. Xu, F.S.C. Lee, Chemosphere 42 (2001) 245.

[23] P. Castells, F.J. Santos, M.T. Galceran, J. Chromatogr. A 1010 (2003) 141

[24] S. Lundstedt, P. Haglund, L. Oberg, Anal. Chem. 78 (2006) 2993.

[25] N.D. Forsberg, G.R. Wilson, K.A. Anderson, J. Agric. Food Chem. 59 (2011) 8108.

[26] F. Reisen, S. Wheeler, J. Arey, Atmos. Environ. 37 (2003) 3653.

[27] A. Albinet, E. Leoz-Garziandia, H. Budzinski, E. Villenave, J. Chromatogr. A 1121 (2006) 106.

[28] W. Wang, N. Jariyasopit, J. Schrlau, Y. Jia, S. Tao, T.W. Yu, R.H. Dashwood, W. Zhang, X. Wang, S.L.M. Simonich, Environ. Sci. Technol. 45 (2011) 6887.

[29] P. Di Filippo, C. Riccardi, C. Gariazzo, F. Incoronato, D. Pomata, S. Spicaglia, A. Cecinato, J. Environ. Monit. 9 (2007) 275.
[30] H.A. Bamford, D.Z. Bezabeh, M.M. Schantz, S.A. Wise, J.E. Baker, Chemosphere 50 (2003) 575

[31] J.O. Allen, N.M. Dookeran, K. Taghizadeh, A.L. Lafleur, K.A. Smith, A.F. Sarofim, Environ. Sci. Technol. 31 (1997) 2064.

[32] C.H. Hung, H.P. Ho, M.T. Lin, C.Y. Chen, Y.Y. Shu, M.R. Lee, J. Chromatogr. A 1265 (2012) 1.

[33] W.X. Qi, H.J. Liu, J.H. Qu, C.Z. Hu, H.C. Lan, M. Berg, H.M. Ren, W. Xu, Environ. Monit. Assess. 177 (2011) 467.

[34] W.X. Qi, H.J. Liu, J.H. Qu, H.M. Ren, W. Xu, Environ. Sci. Pollut. Res. 18 (2011) 346

[35] J. Cristale, J. Quintana, R. Chaler, F. Ventura, S. Lacorte, J. Chromatogr. A 1241 (2012) 1.

[36] O.L. Chapman, D.C. Heckert, J.W. Reasoner, S.P. Thackaberry, J. Am. Chem. Soc. 88 (1966) 5550

[37] Y.G. Jiao, Y. Ma, T.Q. Li, H.T. Yu, J. Cent. Univ. Nat. 14 (2005) 108 (in Chinese).

[38] B.X. Mai, J.M. Fu, G.Y. Sheng, Y.H. Kang, Z. Lin, G. Zhang, Y.S. Min, E.Y. Zeng, Environ. Pollut. 117 (2002) 457.

[39] EPA Method 8000B http://www.epa.gov/wastes/hazard/testmethods/sw846/ pdfs/8000b.pdf

[40] G. Yu, X.B. Xu, Chemosphere 24 (1992) 1699. 